\title{
Hermes no está dentro de la estatua (El aristotelismo de Acosta)
}

\author{
Víctor Hugo Martel Paredes \\ Universidad Nacional Mayor de San Marcos \\ hmartelp@hotmail.com
}

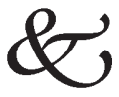

Resumen

No solo la filosofía, sino también la política, economía, cultura y educación latinoamericanas parecen seguir la tendencia europea; sin ánimo de comprender el propio mundo en torno, hay un esfuerzo por modular la realidad a las leyes y principios ajenos, cuando debería ser al revés. Esta tendencia tiene sus raíces en la definición del habitante de las tierras de ultramar durante la segunda escolástica. Cuando América fue descubierta por los españoles, las discusiones acerca de lo que el ser humano podía ser ya estaban casi cerradas, las especies en el arca de Noé ya estaban contabilizadas, las certezas del mundo ya estaban aseguradas por los bien definidos contornos escolásticos. El sílabo de filosofía que José de Acosta propone es una interpretación de Aristóteles que linda con la heterodoxia y que, al mismo tiempo, supone un concepto del indígena americano que, aunque no lo ubica como descendiente de Adán, permite su evangelización.

Palabras claves: José de Acosta, sílabo, segunda escolástica, indígena americano.

\begin{abstract}
Not only phylosophy, but also the economy, culture and education in Perú seems to follow the european trend. Without wishing to understand the world around us, every single effort to explain our world is an effort to modulate our reality to foreign laws ands principles, when it should be backwards. This trend has its roots in the definition that is given to Nature Americans in the second scholastic. When Spain dicovered America the discussions about what the human being could be were already closed. The species of the Noah's Ark were recorded, the certainties of the world was guarantead by a scholastic framwork. The sy-
\end{abstract}


llabus of philosophy that José de Acosta proposes is an interpretation of Aristotles theory, that borders on heterodoxy and at the same time is a concept about the definition of the Nature Americans, which althought not located them as descendents of Adam, allows their evangelization.

Key words: José de Acosta, Syllabus, second Scolastic, Nature American.

\section{Introducción}

El sílabo propuesto por Acosta se presenta ante los ojos como el testimonio de una época bullente en discusiones y rico en diversidad interpretativa. Mal comprendida, la escolástica es percibida como decadente por el método que es aceptado convencionalmente, por el núcleo religioso que es visto como estancamiento, pero el esfuerzo de preservar la pureza evangélica en un mundo desbordante de doctrinas, permitió la gestación de un mundo completamente ajeno al deseado por sus agentes, emergente en los intersticios de las disputas.

Esta presentación comprende cuatro partes: primera, una breve reseña biográfica de Acosta; la segunda, la doctrina de Aristóteles, descrita sucintamente; la tercera, en la que se señalan los puntos de aceptación y rechazo de Acosta a Aristóteles y finalmente, un intento de interpretación del sílabo propuesto por Acosta.

\section{José de Acosta}

A fines del siglo XV e inicios del XVI, el cuadro que componían los clarooscuros del mundo se iban coloreando y concretando con la formación de los Estados europeos, forma profana de vida en el pasado, el movimiento de Reforma, peligros externos, autoridades profanas ocupadas de la disciplina del clero y los laicos, teoría autoritaria del Estado pontificio, interés pecuniario de la iglesia, comercio de cargos eclesiásticos e indulgencias y el movimiento de la contrarreforma.

En medio de este clima provocador, en 1540 José de Acosta ve la luz del día en Medina del campo. Ese mismo año, se funda la Compañía de Jesús en España robustecida por el nuevo espíritu renovador cristiano, aunque se considera a la compañía de Jesús como "una gran fuerza antiprotestante"(Rivara de Tuesta, M. 1970, p.35), eso no quiere decir que su fundador, Ignacio de Loyola, fuese tan solo un antiluterano.

Usualmente se dice que el espíritu moderno transitaba en la compañía de Jesús, fundamentalmente, por dos razones; por un lado, la compañía de Jesús no tiene tradiciones anteriores al siglo $\mathrm{XV}$, por lo cual se afirma que emergió en el seno de la modernidad; por otro lado, la compañía de Jesús contemplaba la misión evangelizadora en distintas comunidades y para todas las clases, 
desde las dominantes hasta las menos favorecidas; por lo tanto, necesitaban de principios que les permitiera flexibilizar el dogma cristiano e insertarlo en distintas regiones.

José de Acosta fue tempranamente admitido a la también naciente compañía de Jesús. "De su juventud han sido publicadas varias Cartas Cuadrimestres dirigidas a San Ignacio y al P. Diego Laimez: cuatro son de Medina del campo, mientras Acosta, aun niño era novicio y joven estudiante y llevaban las fechas del 31 de Mayo y 30 de setiembre de 1544 y 28 de Abril y 29 de diciembre de 1545..." (ibid., p. 66)

Posteriormente, fue educado en las universidades de Alcalá y de Salamanca, donde los jesuitas estaban por entonces desafiando el dominio de los dominicos en las facultades de teología y filosofía. "Concluidos sus estudios, en los que siempre se distinguió por su aplicación e ingenio, recibió el sacerdocio y regentó varias cátedras en diversos colegios de España” (Barreda, F. 1964, p. 75).

Dada su experiencia y comprobada capacidad, se pensó en enviarlo a Roma, pero se tendrá que confiar en el testimonio de Acosta cuando recuerda que pidió ser enviado a las Indias entre gentes bárbaras a trabajar sin opinión ni honra. De modo que desde 1571 hasta 1586 Acosta residió en Perú; producto de su larga estancia es su obra más recordada, Historia Natural y Moral de las Indias, aunque publicada tardíamente, en 1590, marcó toda una época en la interpretación europea del Nuevo Mundo.

Una vez instalado en Perú, sirvió a la compañía de Jesús recibiendo el honroso encargo de dictar la cátedra de teología que tenían los jesuitas en el Colegio San Pablo, en la ciudad de Lima. De catedrático fue nombrado rector del Colegio en 1575 y un año más tarde ascendió a nivel de Provincial. "Cobró fama en Lima por sus sermones elocuentes y doctos. Enseñó en la Universidad de San Marcos, fue el principal teólogo del tercer concilio de la Iglesia Provincial celebrado en 1581, y sirvió como provincial de su orden. Tan grande era su distinción que Francisco Toledo buscó su compañía y, en realidad, trató de incluirlo en el círculo de sus consejeros” (Brading, D. 1998, pp. 208-209).

En su Historia Natural y Moral de las Indias "se encuentra en Acosta una fuerza aristotélica que ilustra la posición científica muy generalizada en esa época. Aristóteles seguía siendo el centro de todas las disciplinas filosóficas, no solo de la Lógica y la Metafísica sino también de la Física y las Ciencias Naturales. Es por esta razón que no resulta sorprendente que el sílabo que Acosta propuso estuviera destinado al estudio de Aristóteles con énfasis en tres aspectos: la lógica, la filosofía natural y la metafísica. Pero el Aristóteles de Acosta está depurado por el tamiz escolástico; por lo tanto, Acosta tiene cuidado de señalar una introducción al curso por obra de Francisco Toledo. 
Pero el pensamiento de Acosta es un mosaico que hay que mirar a distancia para poder ser comprendido. Acosta no solo recibía influencia de Aristóteles, Santo Tomás, Toledo, San Agustín u otros similares, sino también perseguía la coincidencia con las Escrituras y con el naciente humanismo renacentista. Por lo tanto, aunque asiente con Aristóteles y recomienda la lectura de Toledo, toma distancia de ambos y los refuta. De cualquier modo, el centro sobre el que orbitan todos estos elementos es el aristotelismo, por lo tanto es preciso explicarlo brevemente para entender la distancia que toma de él.

\section{Aristóteles}

Para Aristóteles, muy a diferencia de su maestro Platón, el mundo se explica por sí mismo, no es necesario salir de él. En términos generales todas las cosas del mundo pueden ser comprendidas por sus cuatro aitiai (causas): material, formal, eficiente y final. La materia y la forma (hyle-eidos) son solo separables metodológicamente, pero en realidad son indesligables una de otra. De modo tal que la posibilidad de conocer un objeto (universal) reside en el mismo objeto particular. En el binomio hyle-eidos se hayan razones de los cambios y procesos que se experimentan en el mundo de la vida.

Este primer binomio debe ser complementado con el de dynamis-energeia (potencia-acto); esto permite explicar todo tipo de movimiento, desde el físico (traslación) hasta el generativo (cambios cualitativos). La potencialidad debe ser entendida como la posibilidad de llegar a ser algo; en cambio, la actualidad es el cumplimiento efectivo de la esencia, dicho esto se puede entender que la materia únicamente tiene existencia potencial; es decir, la materia muta, cambia, se corrompe; en cambio, la forma es única, inmutable, es la esencia que permite a un grupo de individuos ser reconocidos en una sola especie. De modo que la materia debe cambiar para poder alcanzar la actualización en un individuo.

Pero el movimiento natural tiene que tener una dirección: generación, crecimiento, perfección, mengua, desaparición; este ciclo eterno tiene un sentido, para comprenderlo habría que explicar el segundo par de aitiai, la causa eficiente y la causa final; la primera señala la función de un objeto y el segundo el propósito que cumple, aquello hacia lo que se dirige. Este segundo binomio de las aitiai está incluido dentro de la relación entre materia y forma. Así, las cuatro causas tomadas como una unidad revisten importancia ontológica: sabiendo la forma, materia, función y finalidad de un objeto, tenemos la definición completa de lo que un objeto pueda ser. "El bien es hacia lo que las cosas tienden".

"Inseparable de la concepción del telos (finalidad) es la idea de que todo lo creado por la naturaleza tiene un ergos, es decir, una función peculiar a él; la naturaleza no hace nada en vano" (Düring, I. 1990, p. 56). 
Entonces, la existencia de cada objeto está justificada por la función que cumple con respecto a la totalidad de las cosas existentes. Pero, ¿cuál es la función del ser humano? ¿Qué lo diferencia de otros animales? Aristóteles se apresura en señalar a la razón como elemento calificador del ser humano. El predominio del alma racional sobre la apetitiva es el elemento calificador en un individuo libre y al mismo tiempo la base sobre la que se erige la jerarquía natural entre los individuos: "quien no pueda gobernarse a sí mismo, es conveniente que sea gobernado por otro".

En la naturaleza no hay nada que sea en vano, cada cosa dentro del mundo cumple una función y finalidad particular, pero todas convergen hacia un único propósito y en esa medida sus fines coinciden. "Habiendo hombres que no pueden gobernarse a sí mismos, han nacido para obedecer y hay hombres que han nacido para mandar; por lo tanto, no pueden existir el uno sin el otro, en esa medida cumplen un mismo fin".

Pero ¿cuál es el fin supremo al que convergen todos los eventos? "Todos los movimientos están conectados y forman una cadena entre sí. Considerada como acontecimiento singular, cada cadena o serie semejante requiere un punto de arranque, pues de otra manera se produce un regreso al infinito, que Aristóteles jamás concede. Por ello, aun para el proceso total de la naturaleza se tiene que postular un punto de arranque absolutamente libre del proceso. El principio del movimiento, en consecuencia, es un postulado lógico" (Íbid., p. 55).

La búsqueda de causas inmanentes a los objetos mismos en el mundo se detiene en el punto en que ya no es posible la experimentación. Aristóteles había propuesto un mundo en el que cada individuo, género y especie pueda ser justificado, encontrando lugares comunes a cada individuo, una jerarquía natural que alcanza al mundo humano, al animal racional, fundamento de sus diferencias.

Con todo, aunque el principio teleológico aristotélico se sostiene sobre la confianza en el silogismo, un sistema autoreferencial, especulativo y no experimental, no es esto lo que se cuestiona en la época escolática por el contrario, el silogismo se eleva como método probatorio por excelencia, pero la experiencia y las declaraciones de la Iglesia exigen la inamovilidad del núcleo de la doctrina aristotélica y, al mismo tiempo, un cambio en elementos de su doctrina que, tratándose de un sistema de múltiples referencias prospectivas, cruzadas, retrospectivas que concuerdan asombrosamente bien, un cambio en uno de sus elementos puede ser tomado, como reformista, tal es el caso de Acosta.

\section{El aristotelismo de Acosta}

La percepción aristotélica del mundo contempla la existencia de los cuatro elementos que lo componen: agua, fuego, aire, tierra; cuya combinación de proporciones da forma al mundo. Así, las esferas de fuego y aire colocadas 
encima de la Tierra se elevaban en virtud de su ligereza en la evanescencia del firmamento. El movimiento diurno no solo lleva tras de si y mueve los orbes celestes como cada día lo vemos en el Sol, la Luna y las estrellas, sino que también los elementos participan de aquel movimiento. La tierra no se mueve porque es inepta por su excesivo tamaño. El agua tampoco tiene movimiento porque está abrazada con la tierra y hace una esfera con ella, lo que no le permite moverse. Pero el aire y el fuego, que son más sutiles y próximos al orbe celeste, participan de sus movimientos y son llevados circularmente.

En la época de Acosta, durante el Renacimiento, se empieza a dudar de las impresiones sensibles. "Las diversas imágenes sensibles son combinadas por la imaginación, los conjuntos de imágenes son combinadas por la razón” (Barreda, F. 1964, p. 77).

Desde este punto de vista, el mundo no puede poseer ni centro, ni circunferencia, pues de ser así estaría en contacto con algo externo que lo limitaría; entonces no sería universo. Donde quiera que el hombre se encuentre, en la Tierra, el Sol o en una estrella, se creerá siempre en el centro del universo. Es, pues, imposible atribuir al universo forma alguna. La Tierra deja de ser el centro absoluto del mundo.

El rechazo a las certezas adquiridas por los sentidos va acompañado por la tendencia anticientifica del humanismo, ahora dominante. "Refiriéndose a esta tendencia anticientifica característica del humanismo ha dicho Randal: 'desde Petrarca en adelante, los humanistas se volvieron con desdén de la naturaleza hacia el hombre. Petrarca desprecia el interés por los populares libros de animales y de viajes. 'Aun si todas estas cosas fueran ciertas, en modo alguno contribuyen a la vida feliz, pues, ¿qué ganaríamos conociendo la naturaleza de los animales, de pájaros, de peces y reptiles si ignoramos a qué raza pertenece el hombre, y no sabemos si nos preocupamos por saber de dónde venimos ni a dónde vamos?" (Rivara de Tuesta, M. 1970, p. 78).

Acosta también es producto del tiempo en que le tocó vivir: pese sus posiciones antagónicas, no abandona el universo aristotélico. Acosta explicaba, con Aristóteles, las antípodas. Los lugares naturales conducían a la ley de atracción por un proceso de simplificación. "La primera teoría tenía que admitir en cada caso terrenal, un apetito, un comienzo de voluntad, fatalmente obligada a dirigirse hacia el centro del mundo" (Barreda, F. 1964, p.82).

Aunque Acosta sea un aristotélico declarado, era también eclesiástico, para quien el dogma católico resuelve toda duda. Interpreta las Escrituras dando a los pasajes toda elasticidad posible, necesaria para hallar confirmación sagrada a sus antojadizas hipótesis. "Las Escrituras, en manos de estos pensadores, hacían prodigios; servían para confirmar las conclusiones más contradictorias, para defender las tesis más opuestas. Era la blanda arcilla maleable, siempre 
dispuesta a ofrecerse al silogismo para que tallara en ella escultura de actitudes más diversas".

Por otro lado, Acosta también es influenciado por el emergente humanismo renacentista. Esta influencia le permite tomar distancia de la doctrina aristotélica y "se encuentra ante la imposibilidad de seguir tratando los hechos y las costumbres como consecuencia de su 'alma racional' y reemplaza este postulado con una invocación al principio supremo del libre albedrío" (Barreda, F. 1964, p. 81).

Como se recuerda, el sistema autoreferencial aristotélico no ofrecía lugar a la precariedad, de modo que, cuando se cuestionaba una parte de su sistema, se seguía una serie de inadecuaciones a las que era preciso oponerse. El espíritu crítico de Acosta contra Aristóteles se pronuncia en tono irónico sobre su cosmología, al llegar a Panamá y al convencerse de la falsedad de algunas afirmaciones aristotélicas que pasaban por dogmáticas.

"Confieso que me reía e hice de los meteoros de Aristóteles y de su filosofía, viendo que el lugar y en el tiempo que conforme a sus reglas básicas había de arder todo y ser un fuego, yo y todos mis compañeros teníamos frío”(Ibíd., p. 78).

Más aún, "no contento con comentar el absurdo de la afirmación aristotélica de que las zonas tórridas del mundo eran inhabitables, Acosta buscó razones para explicar por qué el calor de estas regiones no era tan grande como habían imaginado los antiguos. La causa principal, arguyó, era la simple humedad de los trópicos, añadiendo: "la mayor parte de la América, por estas demasiadas aguas, no se puede habitar..." La simple profundidad de los océanos cuando se combinaba con un sol ardiente y la gran frecuencia de los poderosos vientos, producían unas abundantes precipitaciones que mantenían húmedo y fértil al suelo, fresco y benigno al aire" (Brading, D. 1998, p. 210).

La crítica a la cosmología aristotélica, al concepto de ser humano como animal racional y la percepción del libre albedrío como característica distintiva del individuo, terminó por socavar los cimientos de la jerarquía natural de los individuos. Al momento de hablar acerca del hombre americano, adopta una elevada posición moral a través del humanismo cristiano. No acepta la consideración aristotélica del siervo por naturaleza (como aplicable al indio peruano) y va aun más allá en sus consideraciones pragmáticas de evangelización en las Indias, pues arguye que la fe no puede ser impuesta al hombre.

La peculiaridad del pensamiento de Acosta se revela en uno de sus más recordados libros: Historia Natural y Moral de las Indias. "La historia en la terminología de Acosta corresponde a una 'ciencia' o sea a las 'obras de la naturaleza', y la filosofía se refiere a las obras del libre albedrío, que son los hechos y costumbres de los hombres. La concepción moral del hombre ha quedado formulada por Acosta en términos de libertad, porque entiende que ya no cabe 
denominar al hombre de América como un 'siervo por naturaleza', de acuerdo a la concepción de Aristóteles” (Rivara de Tuesta, M. 1970, p. 81).

Esta particularidad sincrética de Acosta permite entender que la segunda escolástica no puede ser comprendida como una unidad doctrinal, sino como un movimiento cultural librado a antagonismos, no siempre conciliable, materializado en el sílabo diseñado por Acosta para el dictado de la doctrina aristotélica, que es ahora presentado.

\section{El sílabo}

Acerca del contenido del curso, no se puede decir mucho a juzgar por el sílabo, pero se puede deducir la intención de Acosta al recomendar solo tres obras y el orden en que han de ser expuestas.

Acosta dice que no deben exponerse todas las obras de Aristóteles, sino únicamente las que vengan al caso: la lógica, la física natural y metafísica. Resulta evidente el orden que Acosta siguió en su recomendación, pero si se recuerda que en esta época el sentido común ordenaba no confiarse en la percepción sensible al momento de adquirir las evidencias del mundo, sino de la especulación silogística.

Desde este punto de vista, es altamente significativo proponer la lógica como asunto propedéutico al curso y como método capaz de abordar los temas siguientes, más aún si se tiene en cuenta que el comentarista elegido por Acosta fue Francisco Toledo ${ }^{1}$.

Francisco Toledo, en su D. Francisco Toleti Societatis Jesé, Comentaria Una Cum Quastionibus in Universam Aristotelis Logicam impreso en Roma en 1575, fue al que Acosta tomó como modelo de explicación de la lógica aristotélica. El texto de Toledo tiene siete partes. La primera parte: cuestiones sobre dialéctica en general, que viene a ser los preliminares del tratado. La segunda, cuestiones sobre el libro de los cinco universales de Porfirio. Tercera, cuarta, quinta, sexta y séptima: cuestiones sobre cada uno de los libros aristotélicos: Categorías, Perihermenias y Analíticos.

1 Francisco Toledo nació en Córdoba el 11 de octubre de 1533, estudió en la Universidad de Salamanca, siendo discípulo de Fray Domingo de Soto. Se graduó de Maestro de Artes en la Universidad de Zaragoza. Ya siendo sacerdote, ingresó en el noviciado de la Compañía de Jesús, aún novicio fue enviado a Roma, donde explicó Filosofía y teología. En 1594, el papa Clemente VIII hizo al padre Toledo Cardenal de la Santa Iglesia Romana, adjudicándole el título presbiteral de Santa María Transpotina. Poco después, el 14 de febrero de 1596, murió y su cadáver fue sepultado en la basílica de Santa María la Mayor. Solana, Marcial, (1941). Historia de la Filosofía Española, época del Renacimiento (siglo XVI) Tomo II. España: Asociación Española para el Progreso de Ciencias. p. 312. 
Como es evidente, Acosta copió el orden y contenido de este libro al momento de hacer su recomendación, demostrando la alta estima que Francisco Toledo le inspiraba. Pero la obra de Toledo no se limitó a la lógica, sino que ha escrito sobre física, cosmología, psicología, etc. En estos puntos Acosta no toma a Toledo. Esta omisión es bastante elocuente ya que por un lado recuerda la distancia que Acosta toma de Toledo y la intención de las siguientes partes del curso.

Efectivamente, Toledo había sostenido "que la tiranía de los incas justificaba la conquista y dominio de los españoles. Si los crímenes contra natura no ofrecían un pretexto para intervención militar, ¿cómo podría afectar la cuestión el carácter de un régimen político?” (Brading, D. 1998, p. 213). Posición distante del humanismo cristiano de Acosta.

De modo que la física natural aristotélica, desde el punto de vista de Acosta, debía servir de pábulo a la argumentación a favor de la libertad de los indios y reconocer el libre albedrío como componente calificador de humanidad, desdeñando el alma racional y con ello la jerarquía del ser.

En el primer libro de la física, expuesto en el sílabo, como es de esperar, estudia el primer binomio aristotélico hylé-eidos (materia-forma) y se pregunta si la materia es ingenerable e incorrupta, si la potencia de la materia exige la forma, si preexiste algo de la forma en la materia, si la privación es principio natural. Acerca de este orden de ideas se puede decir dos cosas: por un lado, el tono hipotético cuestionador como se tratan los asuntos expuestos, sin afirmar, ni limitar su contenido. Por otro lado, la intención de separar estos dos principios, que para Aristóteles eran indesligables, pero más aun el estatuto de las privaciones.

En el segundo libro de la física se pregunta si la naturaleza actúa por un fin, recordando el teologismo aristotélico, si existen monstruos en la naturaleza y si el fin es causa y principio. En la naturaleza nada es gratuito, todo tiene una función y se pregunta si los monstruos existen en la naturaleza, para concluir que si el fin es causa y principio, nuevamente, no hay casualidad.

La disputa acerca de los monstruos en la segunda escolástica es relevante porque se trataba de proporcionar una definición a los indios. Los monstruos, en esta época, podían ser entes cuya única esencia era la privación. Para Acosta, los monstruos estaban directamente relacionados con el demonio, como fuente y autor de toda idolatría en el Nuevo Mundo. "Aunque Acosta reconoció que muchos naturales tenían una vaga idea del creador del universo, un ser divino similar al Dios desconocido, cuyo altar encontró San Pablo en Atenas, sin embargo atribuyó el predominio de la idolatría a la intervención de Satanás, quien influyó sobre la religión indígena de tal modo que creó una blasfema parodia del cristianismo" (Brading, D. 1998, p. 217). 
Esta intervención de Acosta, aunque parezca antojadiza y arbitraria, tenía por propósito ubicar los monstruos y la total privación de ser como esencia de los indios y calificarlos como individuos libres, susceptibles de ser evangelizados.

Finalmente, la metafísica debía cerrar el círculo de definición de lo que el ser humano podía ser. Las cuatro aitiai (causas) aristotélicas debían proporcionar elementos de definición, del mismo modo como Aristóteles ejemplifica su posición diciendo que una estatua de bronce que representa al Dios Hermes puede ser definida por su materia (bronce), forma (Dios Hermes), función (adoración al Dios) y finalidad (el agrado de Dios), el individuo también era susceptible de definición por causas. Pero, desde el punto de vista expuesto, podemos preguntar, cuestionando, junto con Acosta, si Hermes, el dios mensajero entre el mundo celeste y el mundo terrestre, realmente está en la estatua. Habría que alejarse mucho de Aristóteles para afirmar la existencia independiente de la materia sin la forma o hacer de las privaciones una esencia. Si esto fuera posible, la definición de los indios americanos sería perfectamente compatible con la de una inerte, fría, muda e indiferente estatua de bronce.

\section{Conclusión}

Usualmente se dice que la decadencia de la escolástica comenzó en el siglo XVI "en algo concerniente a la materia de estudios, como era la enorme abundancia de cuestiones inútiles y baldías" 2 .

"La juventud peruana agotaba su inteligencia en disquisiciones de teología escolástica; en el aprendizaje de filosofía de Aristóteles acomodando a los caprichos del catolicismo; y en el estudio del Derecho civil"3.

Pero la decadencia de la escolástica encuentra sus razones no en sus doctrinas, sino en los hombres y métodos científicos. "La escolástica, después de haber llegado a su cumbre en la Suma Theologica, se había dormido en sus laureles y vivía su propia sustancia, infiel al principio de indagación racional"4.

Muy lejos de este cuadro monócromo, la segunda escolástica peruana tenía que vérselas entre el mandato del Rey de España, la coherencia evangélica y la posibilidad de inserir estos modelos al jardín de las especies no descrito en el libro de Dios y , por otro lado, estos pensadores no eran indiferentes, en modo alguno, al humanismo renacentista europeo. Esta situación permitió pensar un mundo multidimensional, atravesado por ases disímiles: político, moral, epistemológico, ontológico, axiomático; pero, que los pensadores de esta época se esforzaron por entender en un solo concepto al que converjan todos.

2 Solana, op. cit., p. 9.

3 Barreda, op. cit., p. 96.

4 Solana, op. cit. p. 11. 
La afluencia de doctrinas era tanta como órdenes había; esta circunstancia permitió una tendencia a la crítica libre y al pensamiento independiente, por supuesto, dentro de los límites de la religión. El núcleo duro e incuestionable seguía siendo el evangelio cristiano, pero sus interpretaciones libres y sincretistas lindaban con la heterodoxia.

José de Acosta representó esta nueva dirección. Pero aunque Acosta guardaba deseos de emancipación intelectual, fue un aristotélico y un fiel obediente de las Sagradas Escrituras.

"Cuando Acosta discute hipótesis de cosmólogos, es un razonador dogmático, apegado a textos de las Sagrada Escrituras"5, pues las veía como fuente última de argumentos y fallos decisivos que resolvían, en última instancia, cualquier controversia científica.

Dogmatismo que parece contradecir su libertad crítica y, por tanto, un retroceso. Pero es explicable en quien es heredero de su tiempo. La obra de Acosta se nos presenta como un ejemplo claro de la transición ideológica sufrida en esta época. Este punto de la historia era, pues, una encrucijada en el sentido pleno y profundo de la palabra, un cruce antagónico de dos culturas, la hispana y la andina: dos tiempos, el moderno y el escolástico, generando un pensamiento quiasmático sincretista que se alimenta en el intersticio en que todas las doctrinas inciden.

\section{Referencias bibliográficas}

ACOSTA, J. (1987). Historia Natural y Moral de las Indias. España: Editorial 16.

BARREDA, F. (1964). Vida Intelectual del Virreinato del Perú. Perú: Universidad Nacional Mayor de San Marcos.

BRADING, D. (1998). Orbe Indiano. De la monarquía católica a la república criolla, 14921867. México: Fondo de Cultura Económica.

DÜRING, I. (1990). Aristóteles. México: Universidad Autónoma de México.

RIVARA DE TUESTA, M. (1970). José de Acosta, un humanista reformista. Perú: Ed Universo. SOLANA, M. (1941). Historia de la Filosofía Española, época del Renacimiento (siglo XVI). España: Asociación Española para el Progreso de Ciencias.

VARGAS, R. (1961). El Perú virreinal. Perú: Editorial Tipografía peruana.

VARGAS, S. (1989). La Singularidad novohispana en los jesuitas del siglo XVIII, México: Editorial UNAM. Instituto de Investigaciones Filológicas, Centro de Estudios Clásicos.

5 Barreda, op.cit., p. 80. 


\section{Apéndice}

\section{Intervenciones y Programas de Acosta en el Programa de Estudios}

\section{Aquello que precedió al primer programa de Estudios editado en 1586}

Lo que hay que enseñar en las Escuelas de Filosofía ${ }^{6}$

Supuestos solo tres años para desarrollar el curso de artes -que me parece bastante suficiente-, no debe exponerse todas las obras de Aristóteles, sino se expongan las que vienen al caso, como la lógica, la física natural y la metafísica. Estas se expondrán con la introducción de D. Toledo, los predicables de Porfirio, los predicamentos de los dos libros de Perihermenias, los dos libros posteriores en lógica. En cuanto a la Física, los ocho libros de la Física, el cuarto del Cielo, el segundo y el tercero del Alma con el Proemio del primero, el cuarto de los Meteoros. Como la Metafísica es la última, se explicará la mayor parte de sus doce libros. Las demás obras necesariamente habrán de dejarse al estudio privado del alumno.

Sobre estos libros no sabría decidirme sin gran trabajo sobre qué cuestiones deben ser tratadas. Esto no sucedió mientras yo dictaba el curso de las artes: tuve que exponer esto, fuera de las que comúnmente se exponen. Por lo cual, tras su examen y el examen de lo que se trata por otros, seleccioné estas materias.

1. si la lógica es necesaria

\section{Cuestiones preliminares}

2. Si ella sea ciencia

3. Si sea una sola ciencia

4. Si sea una ciencia especulativa

5. Si la argumentación sea un sujeto de la lógica

\section{Cuestiones de los universales}

1. Si los universales están en las cosas

2. Si hay cosas antes de la operación del intelecto

3. Si la segunda intención se realiza por noticia comparativa

4. Si el universal está sujeto a la introducción de Porfirio

6 Del Estudio del Código Romano Iff. 110-112, copia. En la parte superior del documento está escrito: "Acosta", de mano del P. Ledesma. 


\section{Cuestiones sobre los predicables}

Sobre el capítulo de la especie: si es verdad lo que Porfirio transmite. Lo mismo sobre cada capítulo.

\section{Cuestiones sobre los predicamentos}

Sobre cada capítulo, antes de los predicamentos, examinar aquellos asuntos que Aristóteles transmite. No puedo decir algo más específico.

Sobre el capítulo de la sustancia: ¿cómo se divide?

¿Se transmite rectamente lo que transmite Aristóteles?

Sobre el capítulo de la cantidad: ¿la cantidad es un género? ¿Es continua o discreta?

¿Es verdadero lo que Aristóteles transmite?

¿Hay género especial de ser para algo?

Examen del mismo capítulo

¿La cualidad es género?

Examinar el resto de los seis predicamentos.

Lo mismo acerca de los post-predicamentos.

¿Hay solo diez predicamentos?

Distinción de estos predicados entre sí.

¿Todos estos diez géneros se dividen realmente?

\section{Sobre Perihermenias}

Sobre la significación y el modo de significar las palabras.

¿Qué es la verdad y en qué sujeto?

Examen de la significación del nombre.

Lo mismo, de la palabra.

Lo mismo, de la oración.

Lo mismo, de la enunciación.

De la división de las cosas. ¿Cómo es esta división?

De los consiguientes

Examinar cada capítulo

\section{Sobre el segundo libro}

\section{Sobre los posteriores}

Examinar el primero y el segundo capítulo

Cómo los accidentes se definen por el sujeto.

Examinar cada capítulo.

Y no se puede decir algo más especial. 


\section{Sobre el segundo libro}

Del orden de las cuestiones.

Examinar cada capítulo.

Del número y diversidad de ellas.

Cómo se demuestra que la cosa es.

Del medio de la demostración principal.

Si los principios "per se" conocidos por intuición se conocen.

\section{Sobre Física \\ Del primer Libro}

Si hay ciencia de las cosas naturales.

Del sujeto de la Filosofía natural.

Si cualquier artífice se demuestra por cualquier género de causas.

Si para el perfecto conocimiento de la cosa se necesario conocer todas sus causas.

Si los universales nos son más conocidos que los singulares.

Si es lo mismo para nosotros lo más conocido y la naturaleza.

Si la sustancia según ella misma es divisible.

Si el todo se distingue realmente de sus partes.

Si las cosas naturales tienen límites ciertos de su cantidad.

Si el término de cantidad de las cosas naturales sea siempre intrínseco.

Si los principios son contrarios.

Si existe la materia.

Si existe la materia de la sustancia.

Si la potencia sea sobre la esencia de la materia.

Si existe algo en la materia que permanezca en la mutación.

Si la materia es ingenerable e incorrupta.

Si la potencia de la materia exige la forma.

Cuáles con los nombres de la materia.

Si preexiste algo de la forma en la materia.

Si la privación es un principio natural.

\section{Del segundo libro}

Si es buena la definición de la naturaleza.

Si todos los seres naturales se dicen naturales por un principio interno activo del movimiento.

Si el movimiento del cielo es natural.

Si la física se distingue de la materia.

Si el físico considera a la materia prima.

Si el arte imita a la naturaleza. 
Si solo existen cuatro géneros de causas.

Si las causas particulares realizan algo.

Si la fortuna y la casualidad existen.

Si las cosas que no suceden siempre ni frecuentemente sean por la casualidad.

Si existe el hado.

Si la naturaleza actúa por un fin.

Si existen monstruos en la naturaleza.

Si el fin es causa y principio.

\section{Del tercer libro}

Si el movimiento existe "per se" en algún predicamento.

Si la acción está en el agente.

Si el movimiento se distingue de su término.

Si es propio del físico tratar del infinito.

Si lo uno es indivisible.

Si el número procede en adelante hacia el infinito.

Si el cuerpo es infinito en acto.

Si el lugar es igual a lo localizado.

\section{Del cuarto libro}

Qué es el lugar.

Si las cosas incorpóreas están en un lugar.

Si la última esfera está en un lugar.

$\mathrm{Si}$, en el caso de que el vacío existiese, existiría el movimiento en el instante.

Si el tiempo es número, movimiento, etc.

Si existe un único ahora en todo el tiempo.

Si todos los seres están en el tiempo.

Si el tiempo es un ente de razón.

Si el tiempo es uno en número.

Si la generación es movimiento.

\section{Del quinto Libro}

Si la unidad específica del movimiento debe ser tomada solo como un término "ad quem".

Si la unidad natural del movimiento se toma de tres.

Si hay dos movimientos en la cosa cuando algo se mueve por un contrario al revés.

\section{Del sexto libro}

Si lo continuo se compone de partes indivisibles.

Si todo lo que se mueve puede moverse más lenta o rápidamente. 
Si todo lo mudable es divisible.

Si en el movimiento se da un primero y un último.

\section{Del sétimo libro}

Si ambas demostraciones de Aristóteles son correctas.

Si lo que se mueve y el movimiento están juntos.

Si solo hay alteración en las cualidades de la tercera especie.

Si resulta comparación solo en la última especie.

Si las reglas tienen fuerza universal, que tratan de la proposición de los movimientos por Aristóteles.

\section{Del octavo libro}

Si el mundo tuvo inicio con un motor en el tiempo.

Si el mundo pudo existir desde la eternidad.

Si el animal se mueve por sí mismo.

Si existe un solo primer motor perpetuo.

Si Dios es de infinito poder.

\section{Sobre el libro de la Generación y de la Corrupción}

Cuál es el sujeto de estos libros.

Si existe generación en las cosas.

Si la generación sea alteración.

Si la alteración tiene necesariamente que anteponerse a la generación.

Si en toda generación resulta una disolución hasta la materia prima en lo sustancial.

O en lo accidental.

$\mathrm{O}$ el mismo efecto puede ser producido por otro agente que el producto .

$\mathrm{O}$ en otro instante que el producto.

Si el aumento es generación.

Qué aumenta si alguna parte suya aumenta.

Si en el aumento permanece el mismo todo antes y después.

Si el aumento se hace según las partes formales y no materiales.

$\mathrm{Si}$ el aumento es movimiento continuo.

Si la rarefacción es aumento.

Si todo agente actúa en sí mismo.

Si lo semejante puede actuar en lo semejante.

Si el agente se repite al actuar.

Si lo indivisible puede alterarse.

Si las formas sustanciales se entienden elementales.

Si los elementos permanecen formalmente en lo mixto. 
Si la mixtura es posible.

Si toda mixtura es natural.

\section{Sobre el segundo}

Si solo hay cuatro cualidades primas.

Si solo hay dos activas y dos pasivas.

Si existen cuatro elementos.

Si son de la misma especie lo cálido del aire y el fuego.

Si hay que poner cualidades virtuales en los elementos.

Si el fuego es primero caliente, etc.

Si la levedad del aire y del fuego es de la misma especie.

Si se da algún elemento puro.

Si cualquier elemento puede transmutarse inmediatamente en otro.

Si es más fácil la transmutación donde los elementos están reunidos.

Si de cualesquiera elementos no reunidos puede generarse algún tercero.

$\mathrm{Si}$, en el caso de que hubiese infinitos elementos, podría haber infinitas contrariedades.

Si cualquier mixto, situado en el lugar central, es compuesto de todas las cosas simples.

Si las cualidades primas son principios activos en la generación mixta de los elementos.

Si se da un mixto proporcionado de elementos.

Si la calidez es más fuerte en la niñez que en la juventud.

Si es perpetua la generación.

Si cualquier ente corruptible tiene un periodo determinado.

Si el tiempo de generación de una cosa es igual que el tiempo de su corrupción. Si las generaciones son un proceso infinito.

Si lo corrupto puede regresar lo mismo en número.

\section{En los libros sobre el Alma}

Las cuestiones que trata Cayetano, por esto no es necesario hablar de ellas aquí. En los libros de Metafísica se trata cuestiones no pertinentes a esta ciencia y se dejan innumerables otras que son de esta ciencia. Vea, pues, el que enseña este curso de artes cómo transmitir esta ciencia en combinación con otras cosas. Se requiere mucha perspicacia para ordenar esta ciencia y sus cuestiones. $^{7}$

7 Monumenta Paedagogica. Lo que haya que enseñar en las Escuelas de Filosofía, pp. 504-505. 
